University of Nebraska - Lincoln

DigitalCommons@University of Nebraska - Lincoln

Agronomy \& Horticulture -- Faculty Publications

Agronomy and Horticulture Department

January 2005

\title{
Maize Radiation Use Efficiency under Optimal Growth Conditions
}

John L. Lindquist

University of Nebraska-Lincoln, jlindquist1@unl.edu

Timothy J. Arkebauer

University of Nebraska-Lincoln, tarkebauer1@unl.edu

Daniel T. Walters

University of Nebraska-Lincoln, dwalters1@unl.edu

Kenneth G. Cassman

University of Nebraska-Lincoln, kcassman1@unl.edu

Achim Dobermann

University of Nebraska-Lincoln

Follow this and additional works at: https://digitalcommons.unl.edu/agronomyfacpub

Part of the Plant Sciences Commons

Lindquist, John L.; Arkebauer, Timothy J.; Walters, Daniel T.; Cassman, Kenneth G.; and Dobermann, Achim, "Maize Radiation Use Efficiency under Optimal Growth Conditions" (2005). Agronomy \& Horticulture -- Faculty Publications. 92.

https://digitalcommons.unl.edu/agronomyfacpub/92

This Article is brought to you for free and open access by the Agronomy and Horticulture Department at DigitalCommons@University of Nebraska - Lincoln. It has been accepted for inclusion in Agronomy \& Horticulture -Faculty Publications by an authorized administrator of DigitalCommons@University of Nebraska - Lincoln. 


\title{
Maize Radiation Use Efficiency under Optimal Growth Conditions
}

\author{
John L. Lindquist,* Timothy J. Arkebauer, Daniel T. Walters, Kenneth G. Cassman, and Achim Dobermann
}

\section{ABSTRACT}

Accurate measurement of crop growth and radiation use efficiency (RUE) under optimal growth conditions is required to predict plant dry matter accumulation and grain yield near the genetic growth potential. Research was conducted to quantify the biomass and leaf area index (LAI) accumulation, extinction coefficient, and RUE of maize (Zea mays L.) under conditions of optimal growth. Maize was grown in two environments over five growing seasons (1998-2002). Total aboveground biomass at maturity ranged from $2257 \mathrm{~g} \mathrm{~m}^{-2}$ in 1998 to $2916 \mathrm{~g} \mathrm{~m}^{-2}$ in 2001; values that are considerably greater than the biomass achieved in most previous studies on RUE in maize. Peak LAI ranged from 4.8 to 7.8. Maize extinction coefficients during vegetative growth $(k)$ were within the range of recently published values $(0.49 \pm 0.03)$, with no clear pattern of differences in $k$ among years. Seasonal changes in interception of photosynthetically active radiation (PAR) were similar across all but one year. Estimates of RUE were obtained using the short-interval crop growth rate method and the cumulative biomass and absorbed PAR (APAR) method. Values of RUE obtained using the two methods were $3.74( \pm 0.20) \mathrm{g}$ $\mathrm{MJ}^{-1}$ APAR and $3.84( \pm 0.08) \mathrm{g} \mathrm{MJ}^{-1}$ APAR, respectively, and did not vary among years. This compares to a published mean RUE for maize of 3.3 $\mathrm{g} \mathrm{MJ}^{-1}$ of intercepted PAR (Mitchell et al., 1998). Moreover, RUE did not decline during grain filling. Differences in biomass accumulation among years were attributed in part to differences in observed radiation interception, which varied primarily due to differences in LAI. Maize simulation models that rely on RUE for biomass accumulation should use an RUE of $3.8 \mathrm{~g} \mathrm{MJ}^{-1}$ APAR for predicting optimum yields without growth limitations.

$P^{\prime}$ LANT DRY MATTER accumulation depends on the total C fixed by photosynthesis and the fraction of that C converted to dry matter (Norman and Arkebauer, 1991). In the absence of biotic and abiotic stresses, plant dry matter accumulation depends on the quantity of radiation absorbed by the canopy (e.g., Kiniry et al., 1989; Monteith, 1977; Sinclair and Muchow, 1999). The relationship between plant dry matter and radiation intercepted has been termed the radiation use efficiency (RUE, g $\mathrm{MJ}^{-1}$; Monteith, 1977). A number of crop growth simulation models have been developed using the RUE concept to forecast crop growth and yield in different environments (Brisson et al., 2003; Jones and Kiniry, 1986; Muchow et al., 1990). These models generally calculate daily biomass production as the product of the quantity of radiation intercepted and RUE (Lecoeur and Ney, 2003). However, the empirical nature of RUE and the low precision with which it can be estimated (Mitchell et al., 1998) may cause significant uncertainty about the accuracy of model simulations. Considering this, Loomis

Dep. of Agron. and Hortic., Univ. of Nebraska-Lincoln, P. O. Box 83095, Lincoln NE 68583-0915. Received 15 Mar. 2004. *Corresponding author (jlindquist1@unl.edu)

Published in Agron. J. 97:72-78 (2005).

(c) American Society of Agronomy

677 S. Segoe Rd., Madison, WI 53711 USA and Amthor (1999) suggested that the RUE era in crop modeling should be closed.

A number of factors contribute to the variation in reported estimates of RUE (Sinclair and Muchow, 1999). Estimates of RUE depend on whether radiation is measured as total solar radiation or as PAR. While some authors suggest that conversion of RUE based on solar radiation to that based on PAR is achieved simply by multiplying by the fraction of total solar radiation that is photosynthetically active (usually 0.5 , Sinclair and Muchow, 1999), it has been pointed out that the appropriate multiplication factor depends on canopy LAI (Bonhomme, 2000). The radiation intercepted by a crop is different from that absorbed by it and, therefore, introduces variation in RUE calculations. In agreement with Sinclair and Muchow (1999), Bonhomme (2000) suggests that assuming $85 \%$ of intercepted PAR (IPAR) is absorbed by the leaf canopy is accurate when canopy LAI is large, but the value is smaller when canopies are less dense. Variation in estimates of RUE can be substantially reduced by measuring both intercepted and absorbed radiation continuously during a sampling period.

Maize grain yield is determined, in part, by kernel number at harvest (Tollenaar et al., 2000), which is sensitive to environmental conditions (Lizaso et al., 2003) and not completely dependent on total biomass production (Rajcan and Tollenaar, 1999). The most effective approach to predicting kernel number per plant depends on the average daily IPAR around silking (Lizaso et al., 2003). Therefore, accurate prediction of daily IPAR is often a critical component of maize simulation models because it determines daily biomass increase as well as kernel number. Radiation interception is primarily determined by the LAI (Bonhomme, 2000; Lindquist and Mortensen, 1999; Muchow, 1988) and an index of the efficiency of radiation interception, the extinction coefficient ( $k$; Lizaso et al., 2003).

The definition of plant growth also determines the estimated value of RUE. Growth can be determined using net $\mathrm{CO}_{2}$ uptake, total aboveground dry matter, or total dry matter (including roots, Arkebauer et al., 1994). Growth is most commonly reported based on net aboveground biomass production because destructive sampling of biomass is easier than long-term measurement of canopy $\mathrm{CO}_{2}$ uptake, and obtaining estimates of root biomass is difficult (Sinclair and Muchow, 1999). Accuracy of measured crop biomass can contribute greatly to variation in estimated RUE, and care must be taken

Abbreviations: APAR, absorbed photosynthetically active radiation; CGR, crop growth rate; DOY, day of year; DVS, development stage; IPAR, intercepted photosynthetically active radiation; $k$, extinction coefficient; LAI, leaf area index; PAR, photosynthetically active radiation; RUE, radiation use efficiency. 
to minimize experimental error (Sinclair and Muchow, 1999).

Considerable debate has occurred on how measurements of crop biomass and radiation interception data should be used to calculate RUE. The crop growth rate (CGR) determined between two consecutive harvests divided by the quantity of radiation intercepted during that period is one method of calculating RUE. This method results in the least bias because CGR values are independent. Sinclair and Muchow (1999) suggested that the linear relationship between biomass accumulation and cumulative radiation interception provides a more appropriate estimate of RUE. While this method has been the most common means of estimating RUE, it has been criticized because use of cumulative data has logical and arithmetic weaknesses (Demetriades-Shah et al., 1992, 1994).

Theoretical estimates of maize yield potential (Tollenaar, 1983) and examples where growers have achieved grain yields near $20 \mathrm{Mg} \mathrm{ha}^{-1}$ exist (Tollenaar and Lee, 2002). Ability to predict crop growth and grain yield at this level of production depends on the value of RUE used in simulations. Therefore, it is critical that estimates of crop growth and RUE be obtained under optimal growth conditions. Loomis and Amthor (1999) estimated the potential maize RUE at $4.9 \mathrm{~g}$ of total biomass production per unit APAR (g MJ ${ }^{-1}$ APAR), but few examples of measured RUE exceed a value of $3.4 \mathrm{~g}$ $\mathrm{MJ}^{-1}$ based on IPAR (Mitchell et al., 1998, Sinclair and Muchow, 1999). Experiments were established to estimate the yield potential of maize under near-optimal growth conditions, and grain yields of $14 \mathrm{Mg} \mathrm{ha}^{-1}$ have been achieved (Yang et al., 2004). The objective of this research was to determine if the biomass and LAI accumulation, extinction coefficient, and RUE of maize under these conditions differ substantially from those reported in the literature.

\section{MATERIALS AND METHODS}

\section{On-Farm Study at Sterling, Nebraska}

Measurements of maize growth and radiation attenuation were made in 1998 on the Beaver family farm near Sterling, NE (402 $26^{\prime} 45^{\prime \prime} \mathrm{N}, 97^{\circ} 36^{\prime} 25^{\prime \prime} \mathrm{W} ; 365 \mathrm{~m}$ above sea level). The Beavers have consistently ranked in the top three maize producers in the irrigated class of the National Corn Growers Association's Yield Contest, producing nearly $19 \mathrm{Mg} \mathrm{ha}^{-1}$ grain $(15.5 \%$ moisture content) in most years. The farm is located on a deep Kennebec silt loam soil (fine-silty, mixed, superactive, mesic Cumulic Hapludoll). Average soil test values in 0 - to $30-\mathrm{cm}$ depth were $\mathrm{pH} 5.6,16 \mathrm{~g} \mathrm{~kg}^{-1}$ soil organic C, $95 \mathrm{mg} \mathrm{kg}^{-1}$ Bray-P, and $299 \mathrm{mg} \mathrm{kg}^{-1}$ exchangeable $\mathrm{K}$.

The sampled field was in continuous maize for at least 5 yr. Tillage included fall disc followed by moldboard plow to a depth of 30 to $35 \mathrm{~cm}$, field cultivation $1 \mathrm{~d}$ before planting, and a ridging operation with an interrow cultivator at the $\mathrm{V} 6$ stage of crop development [ 1 June, day of year $(\mathrm{DOY})=152$ ]. Anhydrous ammonia was applied to the field at $225 \mathrm{~kg} \mathrm{~N} \mathrm{ha}^{-1}$ on 1 April $(\mathrm{DOY}=91)$. Maize hybrid Pioneer 33A14 was planted to achieve 8.9 plants $\mathrm{m}^{-2}$ on 23 April $(\mathrm{DOY}=113)$, and emergence occurred on 1 May $(\mathrm{DOY}=121)$. Chlorpyrifos [O,O-diethyl $O$-(3,5,6-trichloro-2-pyridinyl) phosphorothio- ate] (1 $\mathrm{kg}$ a.i. ha $\left.{ }^{-1}\right)$, alachlor [2-chloro- $N$-(2,6-diethylphenyl)$\mathrm{N}$-(methoxymethyl)acetamide] $\left(1.4 \mathrm{~kg}\right.$ a.i. ha $\left.{ }^{-1}\right)$, and atrazine [6-chloro- $N$-ethyl- $N^{\prime}$-(1-methylethyl)-1,3,5-triazine-2,4-diamine] $\left(0.85 \mathrm{~kg}_{\text {a.i. }} \mathrm{ha}^{-1}\right)$ were applied at planting for rootworm and weed control, respectively. Fertilizer P $\left(29 \mathrm{~kg} \mathrm{ha}^{-1}\right), \mathrm{K}$ $\left(9.4 \mathrm{~kg} \mathrm{ha}^{-1}\right)$, and $\mathrm{Zn}\left(8 \mathrm{~kg} \mathrm{ha}^{-1}\right)$ were applied $5 \mathrm{~cm}$ below and to the side of the seed at planting. Water was supplied through furrow irrigation every 3 to $5 \mathrm{~d}$ beginning immediately after the ridge operation. Maize anthesis occurred on 7 July $(\mathrm{DOY}=188)$ and physiological maturity on 27 August $($ DOY $=239)$. A significant hail event partially defoliated maize plants on 5 July $($ DOY $=186)$.

A 24 (32 rows)- by 38-m section of the Beaver farm was used for destructive and nondestructive plant and soil sampling. The area was separated into four "replicate" blocks, each 16 rows by $19 \mathrm{~m}$ long. Within each block, a $2-\mathrm{m}$ section of row was destructively harvested once every 3 to $7 \mathrm{~d}$ throughout the growing season (21 samples total). Each harvested area was at least $2 \mathrm{~m}$ and/or two rows from previously harvested areas to avoid edge effects. At sampling, height of each plant was recorded and plants clipped at the soil surface and then separated into green and dead leaves, stems, and reproductive organs. Green leaf area was measured using a planometer (model LI3100, LI-COR Inc., Lincoln, NE) and all organ groups dried at $60^{\circ} \mathrm{C}$ to constant weight.

\section{Field Experiments at Lincoln, Nebraska}

A field experiment was established in 1999 on a deep Kennebec silt loam soil (fine-silty, mixed, superactive, mesic $\mathrm{Cu}$ mulic Hapludoll) in Lincoln, NE (40 $49^{\prime}$ N, $98^{\circ} 39^{\prime}$ W; 357 m above sea level). The field was in a sorghum [Sorghum bicolor (L.) Moench]-soybean [Glycine max (L.) Merr.] rotation before 1999, with no $\mathrm{N}$ fertilizer added for at least $10 \mathrm{yr}$. Average initial soil test values in 0 - to $20-\mathrm{cm}$ depth were $\mathrm{pH} 5.3,16 \mathrm{~g}$ $\mathrm{kg}^{-1} \mathrm{C}, 67 \mathrm{mg} \mathrm{kg}^{-1}$ Bray-P, and $350 \mathrm{mg} \mathrm{kg}^{-1}$ exchangeable $\mathrm{K}$. Lime was applied in 1999 and 2001 to maintain soil $\mathrm{pH}$ at about 6.2.

The $3 \times 3 \times 2$ factorial experiment was conducted in a split-split plot randomized complete block design (four replicates) with three crop rotations (continuous maize, maizesoybean, soybean-maize) as main plots, three plant population (P) densities as subplots, and two levels of fertilizer nutrient management $(\mathrm{M} 1=$ recommended fertilizer rates; $\mathrm{M} 2=$ intensive nutrient management) as sub-subplots (Table 1; Yang et al., 2004). Sub-subplots were eight rows $(6.1 \mathrm{~m}$ at $0.76-\mathrm{m}$ row spacing) by $15 \mathrm{~m}$. Results presented here were obtained from the soybean-maize rotation main plot and the intensive management (M2) treatments during the 1999 to 2001 period and the maize-maize rotation M2 treatments in 2002. Only the highest population treatments were analyzed in 1999 and 2000, whereas all three or two (highest and lowest) population treatments were evaluated in 2001 and 2002, respectively.

The experiment was managed intensively to ensure optimal water and nutrient conditions and avoid stresses from weeds, insects, and diseases. The field was ripped to a depth of $45 \mathrm{~cm}$ in the fall of 1999 and fall moldboard plowed to $30 \mathrm{~cm}$ in each year to create a deeper topsoil layer. Experiments were irrigated to fully replenish daily crop evapotranspiration via a surface drip tape system in 1999 and 2000, with the tape placed next to the plants in each row. A subsurface drip irrigation system was installed in 2001 with drip tapes in alternate rows at about 30- to 37-cm depth. Corn hybrid Pioneer 33A14 (Bt) was planted in 1999 and 2000 and Pioneer 33P67 in 2001 and 2002. In the corn-soybean rotation, a high-yielding, semideterminate soybean cultivar, NE3001, was planted in all 
Table 1. Maize hybrids, final population density, and date (day of year, heat units accumulated from emergence in parentheses) of sowing, emergence, initiation, and conclusion of photosynthetically active radiation (PAR) measurements, anthesis, and physiological maturity.

\begin{tabular}{|c|c|c|c|c|c|c|c|c|}
\hline Year & Hybrid & $\begin{array}{c}\text { Population } \\
(\text { P1, P2, P3) } \dagger\end{array}$ & Sowing & Emergence & $\begin{array}{c}\text { PAR initiated } \\
\text { DOY (TU) } \div\end{array}$ & $\begin{array}{l}\text { PAR concluded } \\
\text { DOY (TU) }\end{array}$ & $\begin{array}{c}\text { Anthesis } \\
\text { DOY (TU) }\end{array}$ & $\begin{array}{c}\text { Maturity } \\
\text { DOY (TU) }\end{array}$ \\
\hline 1998 & 33A14 & 8.9 & 113 & 121 & $173(404)$ & 244 (1238) & $188(590)$ & 239 (1177) \\
\hline 1999 & 33A14 & 11.3 & 133 & 141 & 210 & 256 (1509) & $200(706)$ & 256 (1509) \\
\hline 2000 & 33A14 & 11.0 & 112 & 120 & 208 (1050) & 233 (1441) & 187 (740) & 233 (1441) \\
\hline 2001 & 33P67 & $7.7,10.2,11.2$ & 116 & 122 & $152(228)$ & 239 (1473) & 189 (707) & 243 (1532) \\
\hline 2002 & 33P67 & $7.1,8.4,9.4$ & 130 & 136 & $165(304)$ & 227 (1323) & $199(866)$ & 254 (1713) \\
\hline
\end{tabular}

$\dagger$ P1, P2, and P3 refer to plant density treatments used in the Lincoln field experiment.

† DOY, day of year; TU, thermal units accumulated from emergence.

years. Field cultivation of all plots was done at the V6 stage of corn to incorporate $\mathrm{N}$ fertilizer and control weeds.

Nutrient amounts applied to each maize crop were 225 to $298 \mathrm{~kg} \mathrm{~N} \mathrm{ha}^{-1}, 45 \mathrm{~kg} \mathrm{P} \mathrm{ha}^{-1}$, and $85 \mathrm{~kg} \mathrm{~K} \mathrm{ha}^{-1}$. Nitrogen application included 100 to $105 \mathrm{~kg} \mathrm{~N}^{-1}$ incorporated before planting and two to three sidedress doses at V6, V10, and VT stages of maize, all as ammonium nitrate. Blanket doses of $\mathrm{S}, \mathrm{Fe}$, and Zn were applied in 1999 and 2000 (Yang et al., 2004).

Crop staging was assessed regularly on 10 plants located within the fifth and sixth rows of each sub-subplot. Five consecutive plants were periodically harvested approximately biweekly throughout the growing season in each sub-subplot. Each harvested area was at least $1 \mathrm{~m}$ and/or one row from previously harvested areas to avoid edge effects. At sampling, height of each plant was recorded and plants clipped at the soil surface and then separated into green and dead leaves, stems, and reproductive organs. Green leaf area was measured using a planometer (LI3100) and all organ groups dried at $60^{\circ} \mathrm{C}$ to constant weight.

\section{Canopy Radiation Interception Measurements}

A portable weather station was erected in each experiment to monitor hourly soil, air, and canopy temperatures; incident, intercepted, and reflected PAR; precipitation; relative humidity; and wind speed. The station was placed at Sterling in the field adjacent to the sampled blocks with data collection initiated on 20 June (DOY = 171). In the Lincoln experiment, the station was placed in the field between two blocks and data collection initiated on dates reported in Table 1. Incident quantum flux was measured above the canopy using a point quantum sensor (LI-190SA, LI-COR, Lincoln, NE) in all years. Intercepted quantum flux was measured by the placement of a single-line quantum sensor (LI-191SA, LI-COR, Lincoln, $\mathrm{NE})$ at the soil surface diagonally across rows at Sterling and in the high-population (P3), high-management (M2) treatment in 1999 and 2000; three sensors (one in each of the three population by M2 treatments) in 2001; and two sensors (one in each of the P1 and P3 by M2 treatments) in 2002. Reflected quantum flux was measured using an inverted-line quantum sensor (LI-191SA Idem) attached to the weather station and placed $2 \mathrm{~m}$ above the crop canopy. All measures of quantum flux were then converted to PAR using the conversion $4.6 \mathrm{~mol}$ $\mathrm{MJ}^{-1}$ (Biggs, 1979; Tollenaar and Aguilera, 1992). All sensors had been recently calibrated by the manufacturer (traceable to the U.S. National Institute of Standards and Technology, Gaithersburg, MD), and measured incident radiation was compared to ensure accurate cross-calibration before placement within the canopy. Line sensors were leveled and supported by brackets approximately $10 \mathrm{~cm}$ above the soil surface and cleaned every 3 to $5 \mathrm{~d}$ to ensure accurate measurement. Absorbed PAR was calculated as incident PAR less transmitted and reflected PAR. Reflection of PAR from soil was not measured. Measurements from all sensors were taken once per minute and averaged into 30 -min records.

\section{Calculations and Statistical Analysis}

Corn phenological development was made more comparable across years by defining phenological time using a dimensionless scale ranging from 0 (emergence) to 1.0 (anthesis) to 2.0 (physiological maturity). Rate of development was calculated as the inverse of the number of thermal units accumulated between two phenological events. Thermal units accumulated per day after emergence $\left(\mathrm{TU}_{\mathrm{t}}\right)$ were obtained using $\mathrm{TU}_{\mathrm{t}}=\min \left[\left(30-T_{\mathrm{b}}\right),\left(T_{\mathrm{avg}}-T_{\mathrm{b}}\right)\right]$, where $T_{\mathrm{b}}$ is the base temperature for development $\left(10^{\circ} \mathrm{C}\right), T_{\text {avg }}$ is the average daily temperature $\left(T_{\max }-T_{\min }\right) / 2$, and 30 is the maximum temperature for development.

Total biomass accumulation $\left(W, \mathrm{~g} \mathrm{~m}^{-2}\right)$ and LAI $\left(\mathrm{m}^{2}\right.$ leaf $\mathrm{m}^{-2}$ ground) were determined as the product of measured biomass $(\mathrm{g})$ or leaf area $\left(\mathrm{m}^{2}\right)$ per plant at each sampling date and actual plant density (plants $\mathrm{m}^{-2}$ ). To compare total aboveground biomass at similar phenological development stage (DVS), $W$ was regressed on DVS using the modified Weibull function:

$$
W=W_{\max }\left\{1-\exp \left[-\left(\frac{\mathrm{DVS}}{a}\right)^{b}\right]\right\}
$$

where $W_{\max }$ is maximum estimated aboveground biomass and $a$ and $b$ are shape coefficients. Canopy extinction coefficients $(k)$ were calculated from measurements of transmitted PAR (TPAR, $\mu \mathrm{mol} \mathrm{m} \mathrm{m}^{-2} \mathrm{~s}^{-1}$ ), incident PAR (PAR, $\mu \mathrm{mol} \mathrm{m} \mathrm{m}^{-2} \mathrm{~s}^{-1}$ ), and green LAI on the date of sampling:

$$
k=\frac{-\ln \frac{\mathrm{TPAR}}{\mathrm{PAR}}}{\mathrm{LAI}}
$$

where green LAI was the average across all four replicates of the appropriate treatment (necrotic leaf tissue was not included in green leaf area) and TPAR and PAR were the measured daily totals for the date of sampling. Earl and Davis (2003) showed that daily total PAR interception accurately reflects instantaneous measurement within $30 \mathrm{~min}$ of solar noon. Therefore, our estimates should compare favorably with those reported elsewhere (e.g., Lizaso et al., 2003).

Radiation use efficiency was estimated in two ways. First, the CGR $\left(\mathrm{g} \mathrm{m}^{-2} \mathrm{~d}^{-1}\right)$ calculated between two consecutive sampling dates and averaged across four replicates of the appropriate treatment was regressed on the quantity of APAR (MJ m ${ }^{-2} \mathrm{~d}^{-1}$ ) between those dates. Estimated RUE is the slope of this relationship. Second, total aboveground biomass accumulated beginning after the first destructive sample taken after the PAR sensors were placed in the field was regressed on the quantity of cumulative APAR during the same period. Estimated RUE is the slope of this relationship.

Differences in biomass accumulation through phenological development across years were evaluated by comparing bestfit lines of biomass on DVS using Eq. [1]. Owing to the different sampling times and complex nature of the LAI vs. DVS 
relationship, statistical comparisons were not possible across years. Comparisons of biomass and LAI among treatments at each sampling date were performed by analysis of variance using PROC mixed (SAS Inst., 1999), but only data for the greatest population by M2 treatment are presented. Estimates of RUE among population treatments in 2001 and 2002 were compared by testing the heterogeneity of slopes of the regression of CGR on APAR or cumulative biomass on cumulative APAR (Littell et al., 1991). If differences were not observed among treatments in 2001 or 2002, data within each year were pooled, and estimates of RUE among years were tested using the same approach. If differences were not observed among years, all data were pooled to obtain a single RUE estimate.

\section{RESULTS}

\section{Phenological Development}

Optimum soil water and nutrient conditions were ensured, weeds were aggressively managed to eliminate effects of interspecific competition, and no evidence of pathogen damage was observed in the $5 \mathrm{yr}$ of this research. Thermal time from emergence to maize anthesis or physiological maturity did not vary among treatments in any year. Maize reached anthesis 67, 59, 67, 67, and $63 \mathrm{~d}$ after emergence, and physiological maturity was reached at 126, 115, 112,121, and $118 \mathrm{~d}$ after emergence in 1998, 1999, 2000, 2001, and 2002, respectively (Table 1). Length of the grain-filling period ranged from 46 to $56 \mathrm{~d}$. Thermal units accumulated from emergence to anthesis ranged from 590 to 866 and from 1177 to 1713 for emergence to physiological maturity. Incident PAR accumulated from emergence to anthesis was 794, 599, 782, 729, and 693 MJ in each year, respectively. Higher-than-normal daily average temperatures during grain filling hastened phenological development rate $\left(\mathrm{d}^{-1}\right)$ during grain fill in 2000 (Yang et al., 2004).

\section{Biomass Accumulation}

Comparisons of total biomass and LAI across years only include data from the P3 M2 treatment and the 1998 data from Sterling. Best fit of total aboveground biomass on phenological time was smaller in 1998 compared with other years and larger through the middle of the season in 2002 (analysis not shown, Fig. 1). Total

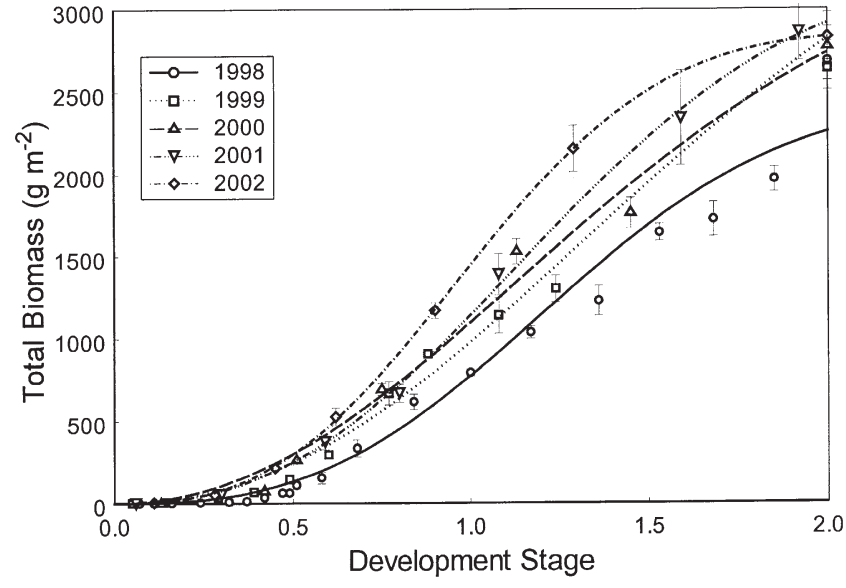

Fig. 1. Observed (symbols and error bars) total aboveground biomass of maize and the best fit of Eq. [1] at Sterling in 1998 through 2002 at Lincoln, NE. Data plotted here are for the greatest-density treatment planted in that year and the M2 fertility treatment. biomass at anthesis, as estimated from the best fit of Eq. [1], was 773, 978, 1097, 1141, and $1445 \mathrm{~g} \mathrm{~m}^{-2}$ in 1998, 1999, 2000, 2001, and 2002, respectively. These estimates are 4 to $95 \%$ larger than the greatest biomass estimates reported at silking $\left(740 \mathrm{~g} \mathrm{~m}^{-2}\right)$ in Tollenaar and Aguilera (1992).

Estimates of biomass at physiological maturity averaged $2257(\mathrm{SE}=151.4), 2822(141.9), 2735$ (170.4), 2916 (257.7), and 2833 (88.0) $\mathrm{g} \mathrm{m}^{-2}$ in 1998, 1999, 2000, 2001, and 2002, respectively. These estimates are 5 to $70 \%$ greater than the greatest biomass estimates reported at physiological maturity for other potential yield research (Tollenaar and Aguilera, 1992; Muchow, 1988, 1989; Westgate et al., 1997) but similar to the greatest values reported in Otegui et al. (1995).

\section{Leaf Area Index, Vegetative Growth, and Intercepted Photosynthetically Active Radiation}

Observed LAI was smallest throughout the season at Sterling in 1998, in part because a hail event immediately before anthesis partially defoliated plants. Leaf area index development was lower in 1998 and 1999 compared with other years (Fig. 2). While LAI at physiological maturity was similar across all years, the lower LAI at anthesis in 1998 and 1999 indicates that the rate of leaf senescence was smaller in those years. A greater rate of leaf senescence in 2000 through 2002 may be the result of higher-than-normal temperatures during the late stages of grain filling in those years (Yang et al., 2004).

Owing to the different sampling times, it was not possible to compare the relationship between the extinction coefficient and DVS across years. Estimates of $k$ appeared to be slightly smaller in 1998 from V9 (DVS = $0.67)$ through early grain fill compared with other years (Fig. 3). Combining all years, estimates of $k$ averaged $0.67( \pm 0.04)$ across the entire season. There was a trend of increasing $k$ values during grain fill. Overall mean estimates of $k$ were $0.49( \pm 0.03)$ for the period between emergence $(\mathrm{DVS}=0)$ and anthesis $(\mathrm{DVS}=1)$ but

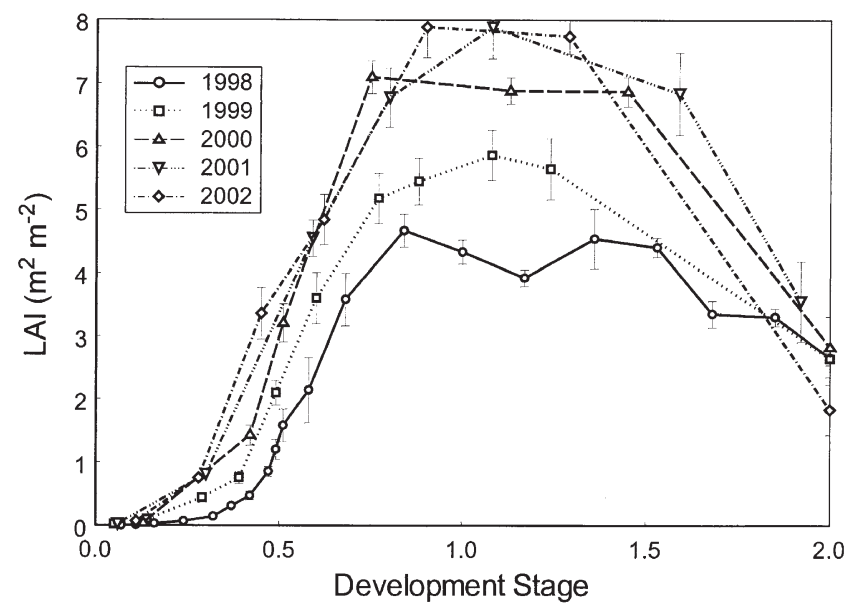

Fig. 2. Observed (symbols and error bars) leaf area index (LAI) of maize at Sterling in 1998 through 2002 at Lincoln, NE. Data plotted here are for the greatest-density treatment planted in that year and the M2 fertility treatment. 


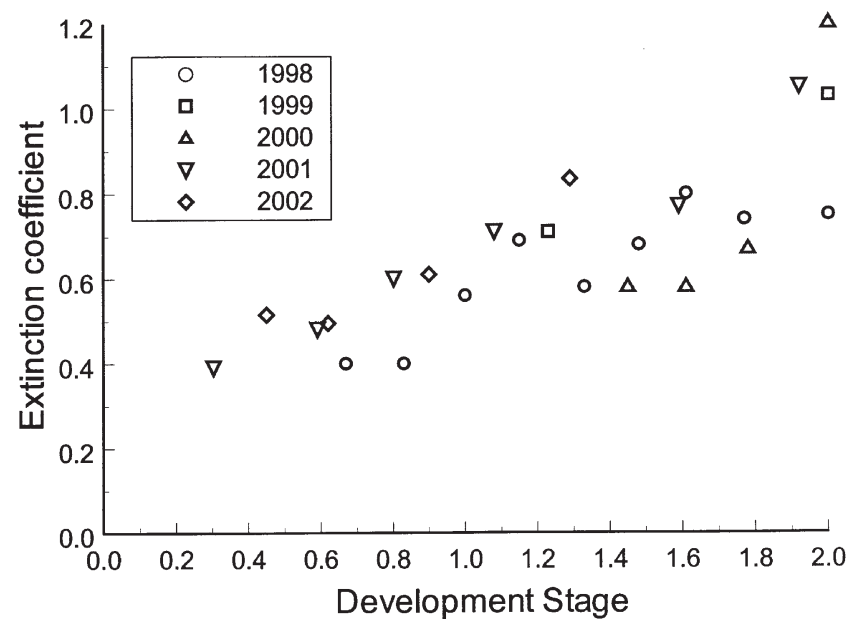

Fig. 3. Seasonal changes in maize canopy light extinction coefficient measured and predicted as a function of a relative phenological development stage ( 0 , emergence; 1 , anthesis; 2 , physiological maturity).

increased to a mean of 0.70 between DVS $=1.0$ and $\mathrm{DVS}=1.8$. The larger estimates of $k$ during late stages of reproduction are likely the result of an increasing proportion of dead leaves intercepting radiation since dead leaf tissue was not removed in the field.

The fraction of PAR intercepted by the maize canopy (IPAR) was lower throughout the measurement period in 1998 than the other 4 yr (Fig. 4). Greatest differences occurred during late vegetative stages and declined through grain filling to where IPAR was only slightly less in 1998 than other years. The lower estimates of the extinction coefficient before anthesis in 1998 could explain some of the differences in IPAR during vegetative growth. However, during grain filling, estimates of $k$ were similar among years, yet IPAR differed. The lower LAI due to hail damage in 1998 also may have contributed to the lower IPAR observed in 1998, especially during grain fill.

\section{Radiation Use Efficiency}

Average season-long CGR was greatest in 1999 (24.6 $\left.\mathrm{g} \mathrm{m}^{-2} \mathrm{~d}^{-1}\right)$ and smallest in $1998\left(22.7 \mathrm{~g} \mathrm{~m}^{-2} \mathrm{~d}^{-1}\right)$.

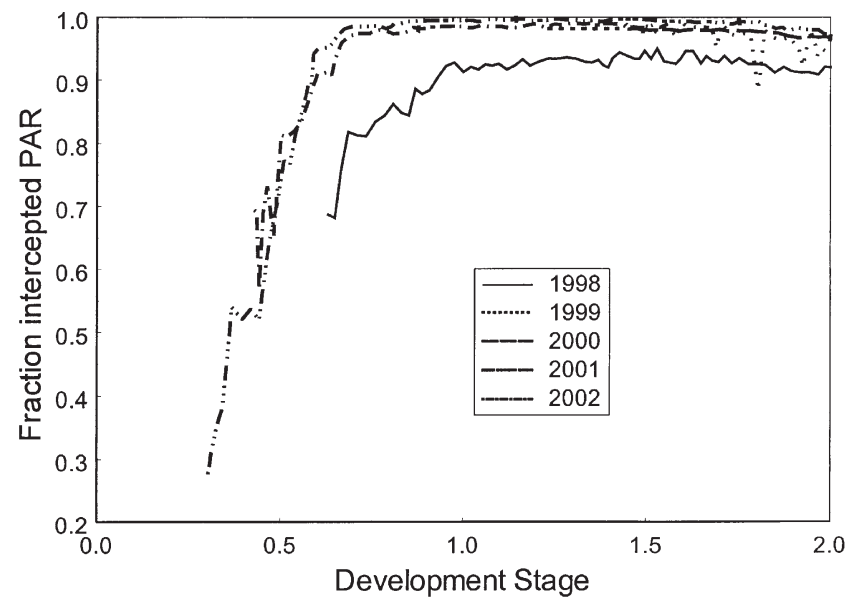

Fig. 4. Seasonal changes in the fraction intercepted photosynthetically active radiation (PAR) in relation to relative phenological development stage ( 0 , emergence; 1 , anthesis; 2 , physiological maturity).

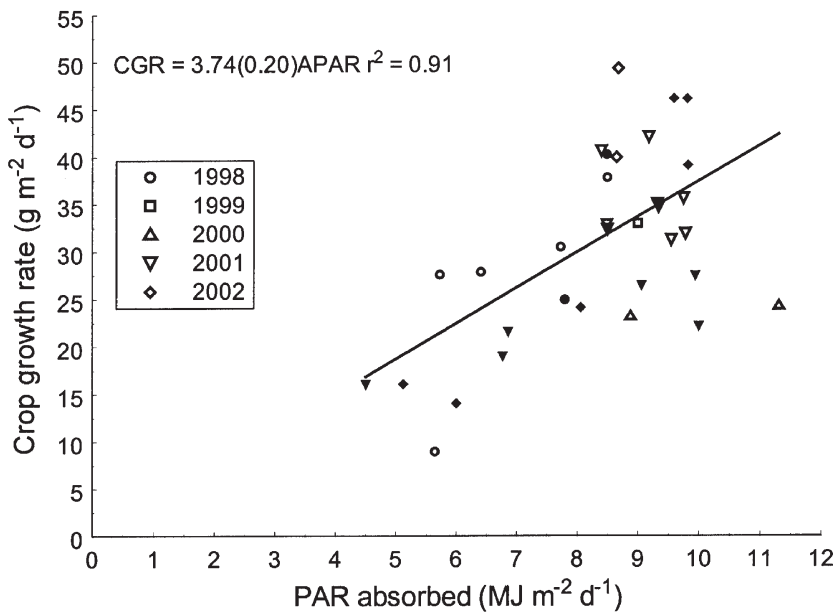

Fig. 5. Maize crop growth rate as a function of absorbed photosynthetically active radiation (APAR). Solid symbols represent observations made during the vegetative stage of development (DVS < 1.0), and open symbols represent observations made during reproductive development $(1.0<$ DVS $<2.0)$. The equation reports the slope $( \pm S E)$ of the regression of crop growth rate (CGR) on APAR with a suppressed intercept (since the intercept did not differ from zero). Residual standard error of the regression was 9.98.

Crop growth rate for specific harvest intervals ranged from 8.9 to $49.3 \mathrm{~g} \mathrm{~m}^{-2} \mathrm{~d}^{-1}$. Crop growth rate values shown in Fig. 5 are within the range of those commonly reported in the literature (e.g., Earl and Tollenaar, 1999; Lemcoff and Loomis, 1986; Rajcan and Tollenaar, 1999).

Slope of the regression of CGR on rate of PAR absorption (APAR) provides an estimate of RUE (the CGR method). Estimates of RUE did not vary among treatments in 2001 or 2002 (analysis not shown). There was only one sampling interval in 1999 and two in 2000 where both radiation interception/absorption and biomass data were collected, so comparisons across years were only possible for 1998, 2001, and 2002. Estimates of RUE did not differ between those years, so all CGR and APAR data were pooled to obtain a single estimate of RUE for all years (Fig. 5). The estimate of 3.74 $( \pm 0.20) \mathrm{g} \mathrm{MJ}^{-1}$ APAR is at the high end of published values of RUE for maize (Mitchell et al., 1998; Sinclair and Muchow, 1999) but considerably below the estimate of potential RUE calculated by Loomis and Amthor (1999). As with the CGR method, all cumulative biomass and APAR data were pooled to obtain a single estimate of RUE across years (Fig. 6). The relationship between cumulative maize biomass and cumulative APAR resulted in a larger estimate of RUE with a lower standard error. However, the estimate of 3.84 $( \pm 0.076) \mathrm{g} \mathrm{MJ}^{-1}$ APAR is not statistically different from the estimate obtained using the CGR method. Average difference between the fraction of IPAR and APAR across all treatments and years was 0.028 ( $\mathrm{SE} \pm 0.003)$. Therefore, RUE based on IPAR can be calculated as the product of RUE based on APAR and 0.972, or $3.63 \mathrm{~g} \mathrm{MJ}^{-1}$ IPAR and $3.73 \mathrm{~g} \mathrm{MJ}^{-1}$ IPAR for the CGR and cumulative methods, respectively.

Muchow and Davis (1988) and Cirilo and Andrade (1994) reported that maximum RUE occurs during vegetative growth and declines during grain filling. Simi- 


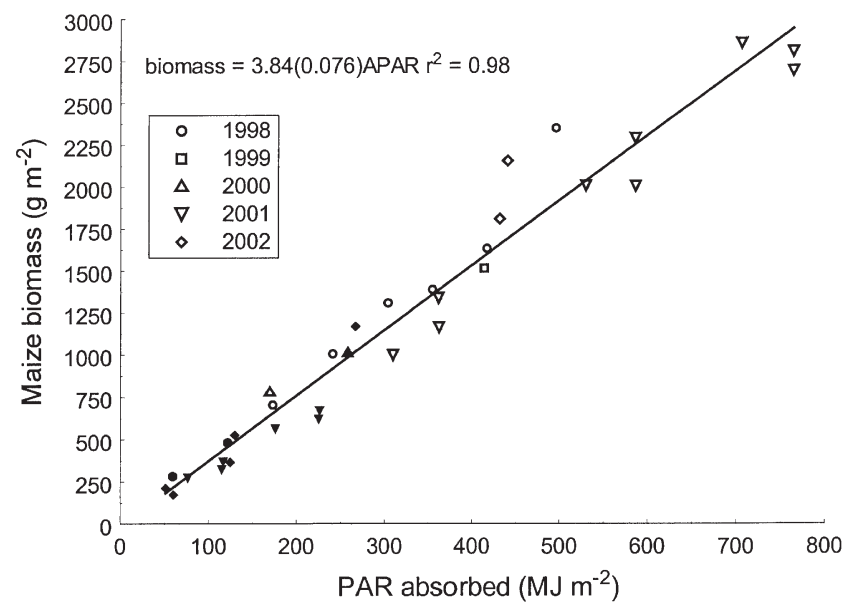

Fig. 6. Cumulative maize aboveground biomass as a function of cumulative absorbed photosynthetically active radiation (APAR). Solid symbols represent observations made during the vegetative stage of development (DVS $<1.0$ ), and open symbols represent observations made during reproductive development $(1.0<$ DVS $<2.0$ ). Note that measurement of APAR was not initiated at emergence. The equation reports the slope $( \pm \mathrm{SE})$ of the regression of cumulative biomass on APAR with a suppressed intercept (since the intercept did not differ from zero). Residual standard error of the regression was 166.2 .

larly, Otegui et al. (1995) estimated the season-long RUE at $3.39 \mathrm{~g} \mathrm{MJ}^{-1}$ IPAR but calculated a larger value during vegetative development (4.14 $\mathrm{g} \mathrm{MJ}^{-1}$ IPAR). Estimates of both biomass accumulation and PAR interception were obtained throughout much of the season in 1998, 2001, and 2002 but only during grain fill in 1999 and 2000. Observations obtained pre- and postanthesis are distinguished by solid and open symbols in Fig. 5 and 6 , respectively. Results do not indicate a reduction in RUE during grain fill.

\section{DISCUSSION}

Experiments conducted in this study were designed specifically to provide near-optimum growing conditions for maize biomass production. Biomass accumulation through time was smallest in 1998; nearly identical in 1999, 2000, and 2001; and greatest in 2002 (Fig. 1). The observed difference in biomass accumulation during development may result from differences in climate, differential absorption of PAR due to variation in plant population and LAI, or to differences in the efficiency of converting APAR into dry matter (Tollenaar and Aguilera, 1992). The fraction of IPAR was shown to differ substantially throughout growth only in 1998. Therefore, the smaller biomass in 1998 may result from reduced PAR absorption, which was primarily due to the lower LAI in that year. The greater biomass accumulation during early reproductive development in 2002 may be the result of a combination of small (undetected) changes in radiation interception, the efficiency in radiation interception, and RUE.

Observed LAI accumulation was greatest and very similar in 2000, 2001, and 2002 but smaller in 1999 and smallest in 1998 (Fig. 2). Plant population was considerably lower in 1998 (Table 1) than those used in the subsequent $4 \mathrm{yr}$, which may have contributed to the smaller early-season LAI. The reduction in LAI due to partial defoliation by hail in 1998 may have resulted in reduced PAR interception during grain fill and contributed to the consistently lower biomass observed in 1998. The smaller LAI observed in 1999 may be due to the considerably later planting, which altered the temperature environment during leaf development, shortened the period from emergence to anthesis by $7 \mathrm{~d}$ compared with the other $4 \mathrm{yr}$ (Table 1), and substantially reduced the potential interception of PAR (since total cumulative incident PAR from emergence to anthesis was 150 MJ smaller than the average for the other $4 \mathrm{yr}$ ). The similarity in LAI observed between 2001 and 2002 indicates that LAI was not related to the larger biomass observed in 2002. Differences in extinction coefficients at constant LAI also would result in differences in radiation accumulation and potential biomass accumulation. However, a clear pattern of differences in $k$ among years was not observed. Therefore, it appears that the LAI observed in 1998 was insufficient to reach maximum radiation interception, resulting in smaller biomass accumulation throughout the season. While the LAI in 1999 was smaller than that observed in later years, it was large enough to reach maximum PAR interception (Fig. 4).

Estimates of RUE obtained using the CGR and the cumulative biomass and APAR methods did not significantly differ, but the CGR method was associated with larger error variance. While there is less variance associated with the cumulative biomass and APAR method, the reduced variance is likely because those data are not truly independent (Demetriades-Shaw et al., 1992). We prefer the short-interval CGR method since data used in its estimate are independent and, therefore, less biased than the cumulative biomass and APAR method. Mitchell et al. (1998) also concluded that the traditional cumulative method of computing RUE tends to give false confidence in the value of RUE and obscures all variation in RUE with time.

Results in Fig. 5 and 6 do not support the common perception that RUE declines during grain fill. Environmental constraints can change shoot biomass by altering leaf area expansion, maintenance respiration, and crop cycle duration (e.g., length of grain fill; Otegui et al., 1995). Changes in these factors may also result in changes in assimilate supply and demand. It appears that, under optimal growth conditions where assimilate supply is likely maintained approximately equal to its demand, CGR is optimized (Rajcan and Tollenaar, 1999), and RUE will not decline.

The RUE measured in this research is greater than any published estimate where PAR absorption was measured continuously throughout the measurement period (Sinclair and Muchow, 1999). Our estimate is also greater than any RUE value used in crop models such as CERESMaize and the Muchow-Sinclair-Bennett model (Muchow et al., 1990). Therefore, it may be expected that these models, as currently parameterized, will not perform well when simulating maize productivity under optimal growth conditions. A recent evaluation of the CERES- 
Maize model for its ability to simulate maize dry matter accumulation under optimal growth conditions confirmed that this model consistently underpredicted biomass yields by 10 to $20 \%$ (Yang et al., 2004). Based on our measurements, we recommend that maize models that rely on RUE for aboveground biomass accumulation should be using a value of at least $3.8 \mathrm{~g} \mathrm{MJ}^{-1}$ APAR or $3.7 \mathrm{~g} \mathrm{MJ}^{-1}$ IPAR for predicting optimum maize grain yield.

\section{ACKNOWLEDGMENTS}

A contribution of the University of Nebraska Agricultural Research Division, Lincoln, NE. Journal Series no. 14531. This research was supported in part by funds provided through the Hatch Act, the Fluid Fertilizer Foundation, the Foundation for Agronomic Research (funds provided by the Potash and Phosphate Institute and IMC Global, Inc.), the Nebraska Corn Board, and the Institute of Agriculture and Natural Resource Sciences, University of Nebraska. We thank Darren Binder, Cheryl Murphy, Doug Miller, Greg Techmeier, T.J. McAndrew, and Michelle Haddix for their outstanding technical support to the field management, plant sampling, and measurement operations.

\section{REFERENCES}

Arkebauer, T.J., A. Weiss, T.R. Sinclair, and A. Blum. 1994. In defense of radiation use efficiency: A response to Demetriades-Shah et al. (1992). Agric. For. Meteorol. 68:221-227.

Biggs, W.W. 1979. Radiation measurement. LI-COR Publ. RMR21084. LI-COR, Lincoln, NE.

Bonhomme, R. 2000. Beware of comparing RUE values calculated from PAR vs. solar radiation or absorbed vs. intercepted radiation. Field Crops Res. 68:247-252.

Brisson, N., C. Gary, E. Justes, R. Roche, B. Mary, D. Ripoche, D. Zimmer, J. Sierra, P. Bertuzzi, P. Burger, F. Bussiere, Y.M. Cabidoche, P. Cellier, P. Debaeke, J.P. Gaudillere, C. Henault, F. Maraux, B. Seguin, and H. Sinoquet. 2003. An overview of the crop model STICS. Eur. J. Agron. 18:309-332.

Cirilo, A.G., and F.H. Andrade. 1994. Sowing date and maize productivity: I. Crop growth and dry matter partitioning. Crop Sci. 34: 1039-1043.

Demetriades-Shaw, T.H., M. Fuchs, E.T. Kanemasu, and I. Flitcroft. 1992. A note of caution concerning the relationship between cumulated intercepted solar radiation and crop growth. Agric. For. Meteorol. 58:193-207.

Demetriades-Shaw, T.H., M. Fuchs, E.T. Kanemasu, and I. Flitcroft. 1994. Further discussions on the relationship between cumulated intercepted solar radiation and crop growth. Agric. For. Meteorol. 68:231-242.

Earl, H.J., and R.F. Davis. 2003. Effect of drought stress on leaf and whole canopy radiation use efficiency and yield of maize. Agron. J. 95:688-696.

Earl, H.J., and M. Tollenaar. 1999. Using chlorophyll fluorometry to compare photosynthetic performance of commercial maize (Zea mays L.) hybrids in the field. Field Crops Res. 61:201-210.

Jones, C.A., and J.R. Kiniry. 1986. CERES-Maize: A simulation model of maize growth and development. Texas A\&M Univ. Press, College Station.

Kiniry, J.R., C.A. Jones, J.C. O’Toole, R. Blanchet, M. Cabelguenne, and D.A. Spanel. 1989. Radiation use efficiency in biomass accumulation prior to grain filling for five grain crop species. Field Crops Res. 20:51-64.
Lecoeur, J., and B. Ney. 2003. Change with time in potential radiation use efficiency in field pea. Eur. J. Agron. 19:91-105.

Lemcoff, J.H., and R.S. Loomis. 1986. Nitrogen influences on yield determination in maize. Crop Sci. 26:1017-1022.

Lindquist, J.L., and D.A. Mortensen. 1999. Ecophysiological characteristics of four maize hybrids and Abutilon theophrasti. Weed Res. 39:271-285.

Littell, R.C., R.J. Freund, and P.C. Spector. 1991. SAS system for linear models. 3rd ed. SAS Inst., Cary, NC.

Lizaso, J.I., W.D. Batchelor, M.F. Westgate, and L. Echarte. 2003. Enhancing the ability of CERES-Maize to compute light capture. Agric. Syst. 76:293-311.

Loomis, R.S., and J.S. Amthor. 1999. Yield potential, plant assimilatory capacity, and metabolic efficiencies. Crop Sci. 39:1584-1596.

Mitchell, P.L., J.E. Sheehy, and F.I. Woodward. 1998. Potential yields and the efficiency of radiation use in rice. IRRI Discussion Paper Ser. 32. IRRI, Manila, Philippines.

Monteith, J.L. 1977. Climate and the efficiency of crop production in Britain. Philos. Trans. R. Soc. London, Ser. B 281:277-294.

Muchow, R.C. 1988. Effect of nitrogen supply on the comparative productivity of maize and sorghum in a semi-arid tropical environment: I. Leaf growth and leaf nitrogen. Field Crops Res. 18:1-16.

Muchow, R.C. 1989. Comparative productivity of maize, sorghum and pearl millet in a semi-arid tropical environment: I. Yield potential. Field Crops Res. 20:191-205.

Muchow, R.C., and R. Davis. 1988. Effect of nitrogen supply on the comparative productivity of maize and sorghum in a semi-arid tropical environment: II. Radiation interception and biomass accumulation. Field Crops Res. 18:17-30.

Muchow, R.C., T.R. Sinclair, and J.M. Bennett. 1990. Temperature and solar radiation effects on potential maize yields across locations. Agron. J. 82:338-342.

Norman, J.M., and T.J. Arkebauer. 1991. Predicting canopy photosynthesis and light use efficiency from leaf characteristics. p. 75-94. In K.J. Boote and R.S. Loomis (ed.) Modeling crop photosynthesis-from biochemistry to canopy. CSSA Spec. Publ. 19. CSSA, Madison, WI.

Otegui, M.E., M.G. Nicolini, R.A. Ruiz, and P.A. Dodds. 1995. Sowing date effects on grain yield components for different maize genotypes. Agron. J. 87:29-33.

Rajcan, I., and M. Tollenaar. 1999. Source:sink ratio and leaf senescence in maize: I. Dry matter accumulation and partitioning during grain filling. Field Crops Res. 60:245-253.

SAS Institute. 1999. SAS system version 8.0. SAS Inst., Cary, NC.

Sinclair, T.R., and R.C. Muchow. 1999. Radiation use efficiency. Adv. Agron. 65:215-265.

Tollenaar, M. 1983. Potential vegetative productivity in Canada. Can. J. Plant Sci. 64:475-485.

Tollenaar, M., and A. Aguilera. 1992. Radiation use efficiency of an old and a new maize hybrid. Agron. J. 84:536-541.

Tollenaar, M., L.M. Dwyer, D.W. Stewart, and B.L. Ma. 2000. Physiological parameters associated with differences in kernel set among maize hybrids. p. 115-130. In M.E. Westgate and K. Boote (ed.) Physiology and modeling kernel set in maize. CSSA Spec. Publ. 29. CSSA and ASA, Madison, WI.

Tollenaar, M., and E.A. Lee. 2002. Yield potential, yield stability and stress tolerance in maize. Field Crops Res. 75:161-169.

Westgate, M.E., F. Forcella, D.C. Reicosky, and J. Somsen. 1997. Rapid canopy closure for maize production in the northern US corn belt: Radiation use efficiency and grain yield. Field Crops Res. 49:249-258.

Yang, H.S., A. Dobermann, J.L. Lindquist, D.T. Walters, T.J. Arkebauer, and K.G. Cassman. 2004. Hybrid-Maize - a maize simulation model that combines two crop modeling approaches. Field Crops Res. 87:131-154. 